\title{
How did the COVID-19 Pandemic Affect Inappropriate Adult Emergency Department Attendances?: A Prospective Cross-Sectional Study
}

\author{
๑ Perihan Simsek, ๑ Engin llhan*, ๑ Ozlem Bulbul*, ๑ Esra Ucuncu*, ๑ Murat Topbas**, \\ (1) Abdulkadir Gunduz* \\ Trabzon University, Faculty of Applied Science, Department of Emergency Aid and Disaster Management, Trabzon, Turkey \\ *Karadeniz Technical University Faculty of Medicine, Department of Emergency Medicine, Trabzon, Turkey \\ **Karadeniz Technical University Faculty of Medicine, Department of Public Health, Trabzon, Turkey
}

\section{Abstract}

\begin{abstract}
Aim: During the coronavirus disease-2019 (COVID-19) pandemic, the strict limitations imposed on access to many healthcare institutions may effect emergency department (ED) attendances with regards to appropriateness. Thus, this study aimed to investigate the urgency level of ED attendances and the frequency of inappropriate use (IU) during the COVID-19 pandemic.

Methods: A prospective cross-sectional study was conducted in the university hospital ED during one week (May 11-17, 2020) of the post-peak period of the first wave of the COVID-19 pandemic. All adult ( $\geq 18$ years) ED attendances were evaluated by emergency residents in terms of clinical and demographic characteristics and appropriateness. The data were recorded on data collection forms.

Results: IU rate detected was $45.1 \%$. In the study, 3.9\% and 9.5\% of attendances were in Emergency Severity Index categories 1 and 2, respectively. A significant negative correlation was found between age and IU (odds ratio=0.978; 95\% confidence interval: 0.960.99). According to the binary logistic regression analysis, it is most likely that IUs are young people who are employed and have no chronic disease.

Conclusion: This study showed that the frequency of IU decreased while the urgency level of the ED attendances increased in the post-peak period of the pandemic compared to a previous study conducted outside of the pandemic, in the same center. There was an inverse relationship between IU frequency and age. The results will help with planning ED services in future pandemic periods.
\end{abstract}

Keywords: Emergency department, COVID-19, inappropriate use, pandemic

\section{Introduction}

Affecting the whole world, coronavirus disease-2019 (COVID-19) infection was defined by the World Health Organization as a pandemic on March 11, 2020 (1). As the COVID-19 pandemic coincides with the seasonal influenza period and being the first center of attendance for infected people, there has been an increase in attendances at alarm levels in some emergency department (EDs) worldwide $(2,3)$. Following the restrictive measures were taken to control the pandemic, ED attendance fell by approximately half (4). This may be owing to reasons such as people's fear of infection or reluctance to place a further strain on the healthcare system (5). However, delaying medical help, despite symptom progression may lead to the progression of the disease and a subsequent increase in very urgent ED attendances $(6,7)$. On the other hand, limited access to health institutions during the pandemic and interruptions in the normal provision of healthcare services may also lead to the use of EDs for health problems that do not require urgent care (8).

The use of EDs for health problems that do not require urgent care is generally called "inappropriate use" (IU). No clear distinction has been made in terms of which attendances are "appropriate" and which are "inappropriate". However, the general approach in the

Address for Correspondence: Perihan Simsek, Trabzon University, Faculty of Applied Science, Department of Emergency Aid and Disaster Management, Trabzon, Turkey Phone: +90 5312633421 E-mail: p_simsek19@hotmail.com ORCID: orcid.org/0000-0002-0216-3968 Received 10.10.2020 Accepted: 10.02.2021

${ }^{\circ}$ Copyright 2021 by The Medical Bulletin of istanbul Haseki Training and Research Hospital The Medical Bulletin of Haseki published by Galenos Yayinevi. 
scientific world is that the appropriateness of the attendance is in line with the urgency level, and attendances that do not require urgent care are inappropriate (9). IU poses an important problem for EDs (10).

The IU of EDs prevents those who are in real need of ED services from benefiting from the limited resources of these departments in the best way possible, and it can lead to increased workloads for healthcare providers and disruption to ED service functions $(9,10)$. It can also increase the costs of health services (11). Moreover, IU can contribute to ED crowding. ED crowding aggravates the workload and prolongs patient waiting times, diagnosis, and treatment processes (12). Furthermore, patients' use of EDs for monitoring chronic diseases deprives them of the preventative, specialized, and ongoing treatment services required to manage these diseases (13).

Examining the urgency level of ED attendances during pandemic periods and determining the IU rate are important for planning service resources, expanding capacity, and increasing efficiency during future pandemics (14). However, few studies have been conducted on how the urgency level of ED attendances is distributed and affected during pandemic periods $(6,7)$.

In a two-seasonal-stage project (no: 216S972) (March and July 2018), the overall IU frequency in three EDs of different levels, including this study center, was found to be extremely high at $75.6 \%$. In this study center only, the IU frequency was $74.1 \%$ in March (15). This study aimed to investigate if the urgency level of ED attendances and IU rate changed during the COVID-19 pandemic period.

\section{Methods}

\section{Study Design and Setting}

Ethical approval (no: 24237859-308) was obtained from the regional scientific research ethics committee. The necessary legal permission for the study was obtained from the Ministry of Health (no: 2020-05-06T041633). The participating patients were informed by the researcher physicians and verbal consent was obtained.

In Turkey, the highest number of daily new COVID-19 cases were reported on April 11th, 2020, the peak of the pandemic, and the pandemic curve began bending as of April 20th, $2020(16,17)$. This cross-sectional study was conducted in the ED of a university hospital in Turkey's Eastern Black Sea Region for a week in the post-peak period of the COVID-19 pandemic (May 11 th-17th, 2020). The ED has 38 beds. Daily attendances numbered around 250 before the pandemic, falling to approximately 100 during the COVID-19 pandemic. The ED serves as an emergency care center where patients who need advanced treatment are transferred from across the city and other provinces in the region. All patients admitted to the ED are assessed by the triage officers and the urgency level is determined according to the color-coding triage system, which was proposed by the Ministry of Health in 2009. According to this system, outpatients whose general condition is stable are green; patients who are at risk of death or limb loss are yellow; urgent patients who need immediate care are coded in red (18).

\section{Selection of Participants}

All ED attendances by adults ( $\geq 18$ ) during the study week constituted the study sample. Patients meeting the following inclusion criteria were included in the study $\geq 18$ years of age, volunteered participants (consent was obtained from relatives of patients who were unconscious because of mental disorders, substance influence, etc.). Attendances to establish vascular access for diagnostic tests (computerized tomography, magnetic resonance imaging, etc.) were excluded.

\section{Data Collection}

In the study period, all ED attendances were evaluated in terms of clinical and demographic characteristics, and appropriateness. The evaluation was prospectively made by ED residents and the data were recorded on the data collection form developed by the researchers based on their experiences and the literature $(9,10)$. In determining the appropriateness of the attendances, the IU criteria used in the project (no: 216S973) conducted by the researchers in 2018 were used (15). The IU criteria are as follows: being in the fifth or fourth category of the Emergency Severity Index (ESI), being able to wait at least 24 hours for medical care without any life-threatening risk or organ dysfunction according to physician assessment, not being referred from another institution, being able to access medical care and treatment required by current health problems from primary care centers, not requiring any surgical procedures.

\section{Emergency Severity Index}

The Emergency Nurses Association and the American College of Emergency Physicians reported five-level systems to be more suitable for determining the urgency level (19). Therefore, the ESI, a five-level triage system, was used to evaluate the urgency and appropriateness of attendance in this study. According to the system, patients are divided into main categories based on symptoms and need for resource use (20).

One week before the data were collected, training on the IU criteria and the ESI was organized for the resident physicians, who evaluated the attendances during the study period. This training included general information and decision points for the ESI 1 [40 minutes (min)], ESI 
2 (30 min), ESI 3-5, and expected resource requirement (30 min), the role of vital findings in ESI (30 min).

\section{Outcomes}

The primary outcomes of the study were the appropriateness and urgency level of the ED attendances. These outcomes were measured according to the criteria mentioned above. The secondary outcomes of the study were the variables that can be related to IU, including demographic characteristics (age, gender, marital status, education, chronic disease, smoking, alcohol use), general characteristics of the attendances (attendance time, arrival type, triage category according to the ESI and color system, number of attendances in the last 6 months), and the clinical features (diagnosis, complaints, time of complaints onset). The diagnoses were presented according to the International Statistical Classification of Diseases and Related Health Problems-10 diagnostic codes.

\section{Statistical Analysis}

The data were analyzed using the IBM Statistical Package for Social Sciences (IBM; Armonk, NY, USA) program. Normal distribution was evaluated with the Kolmogorov-Smirnov test. The relationship between categorical variables was analyzed using the chi-square test. Factors associated with IU were evaluated using binary logistic regression analysis and the analysis results are presented as odds ratios (ORs) and 95\% confidence intervals $(\mathrm{Cl})$. The statistical significance level was set to $p<0.05$. In multiple group comparisons, the significance level was determined according to the Bonferroni correction.

\section{Results}

During the study period, there were 578 adult attendances to the ED where the research was conducted. Of these, 11 patients refused to participate and the study was completed with 567 patients. The IU rate was determined as $45.1 \%$.

The median age of the patients was 49 years (range $=18-101$ years), $55.2 \%$ were male, $82.2 \%$ were married, and $46.2 \%$ had completed primary education. The frequency of IU was found to be lower in patients over 65 years of age compared to other age groups (1840 years, $p=0.000 ; 41-64$ years, $p=0.000$ ). It was found that IU was significantly lower in illiterate patients than other patients $(p=0.000)$, while the IU rate of those with a bachelor's degree or higher education were significantly higher than those with just primary $(p=0.006)$. The IU rate was higher in single people $(p=0.012)$, smokers $(p=0.001)$, and patients without the chronic disease $(p=0.000)$. The IU rate for unemployed people was lower than for others (unemployed and official: $\mathrm{p}=0.001$; unemployed and employed: $p=0.000$; unemployed and other: $p=0.005$ ) (Table 1).

Of the total attendances, 3.9\% were in ESI $1 ; 9.5 \%$ were in ESI 2; $40.9 \%$ in the ESI 3; $31.0 \%$ were in ESI 4 and $14.6 \%$ were in ESI 5 category. According to the color triage system, $25.2 \%$ of the attendances were red, $26.5 \%$ yellow and $48.3 \%$ green. The highest frequency of inappropriate attendances (IA) was seen at night between 24:00 and 07:59, and there was a significant difference between this time interval and daytime (08:00-

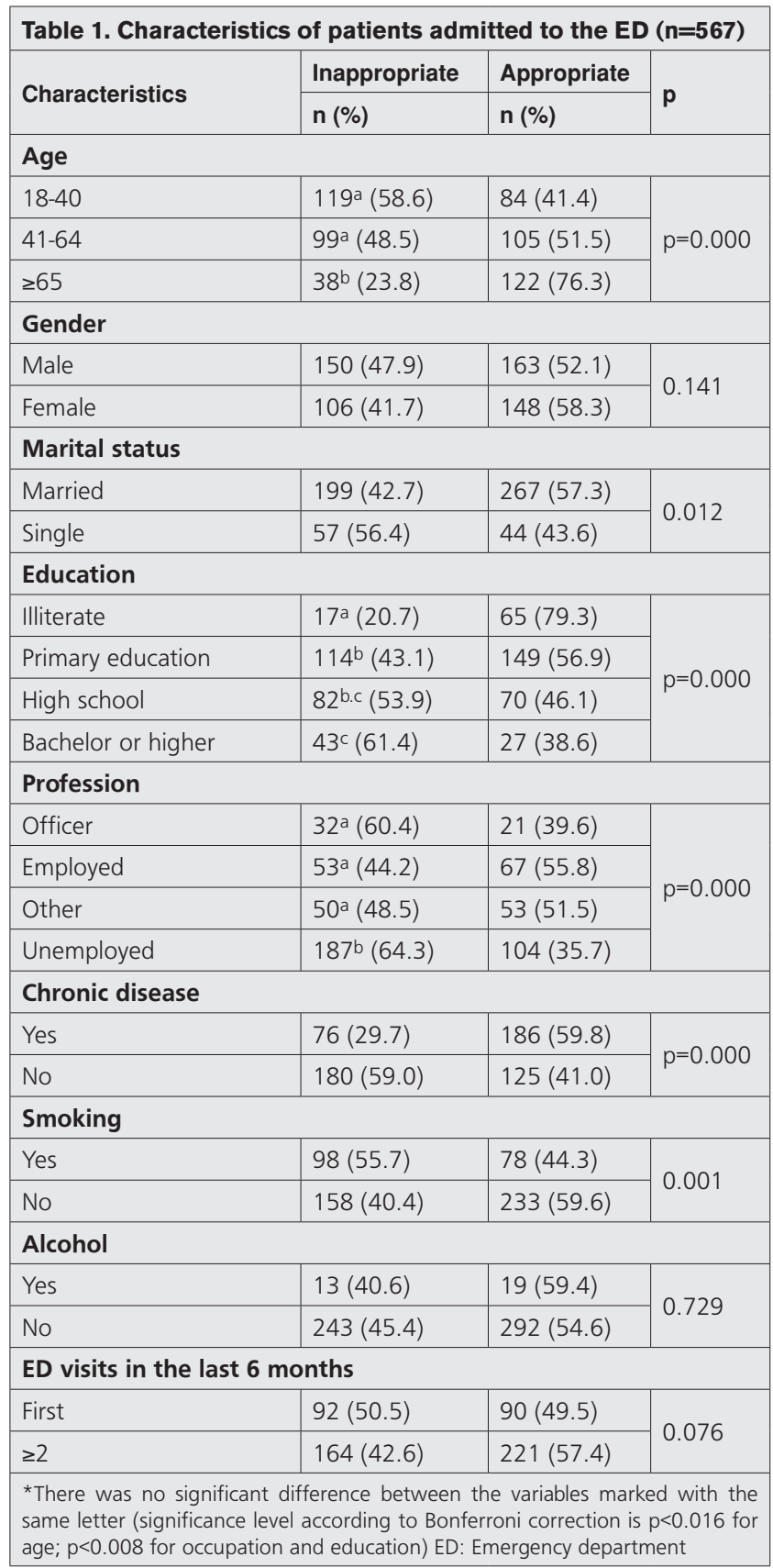


$15: 59)$ in terms of IU rate $(p=0.004)$. IA during the week $(48.9 \%)$ were significantly higher than at the weekend (38.1\%) ( $p=0.013)$ (Table 2).

The most frequent presenting complaint (18.8\%) and diagnosis (14.8\%) in IUs was headache. Appropriate attendances (AAs) were mostly diagnosed with chest pain, falls, nausea, and vomiting (7.1\%), and the most common complaint was abdominal pain (22.2\%) for AAs. The most common attendance time for IA after the onset of symptoms was more than 48 hours (24.6\%), whereas AAs were often made within the first 3 hours of the complaint (42.8\%) (Table 3).

Logistic regression analysis showed that the appropriateness of the attendances increased with age. The analysis revealed that employed people (OR: 1.75; 95\% Cl: 1.12-2.73) and people without chronic disease (OR: 2.22; 95\% Cl: 1.41-3.50) were more likely to make IAs. It was also ascertained that attendances on weekdays (OR: $2.00 ; 95 \% \mathrm{Cl}: 1.33-3.02$ ), at least 12 hours after the onset of symptoms (OR: $3.36 ; 95 \% \mathrm{Cl}: 2.27-4.98)$, and between 24:00 and 07:59 (OR: 1.97; 95\% Cl: 1.14-3.43) were more likely to be inappropriate. It was determined that alcohol users (OR: 0.36; 95\% Cl: 0.15-0.88), and

\begin{tabular}{|c|c|c|c|}
\hline & Inappropriate & Appropriate & \multirow{2}{*}{ p } \\
\hline & n (\%) & n (\%) & \\
\hline \multicolumn{4}{|l|}{ Time } \\
\hline 08:00-15:59 & $88^{a}(40.6)$ & $129(59.4)$ & \multirow{3}{*}{0.013} \\
\hline 16:00-23:59 & 109a.b (44.0) & $139(56.0)$ & \\
\hline 24:00-07:59 & $59^{b}(57.8)$ & $43(42.2)$ & \\
\hline \multicolumn{4}{|l|}{ Day } \\
\hline Weekdays & $181(48.9)$ & $189(51.1)$ & \multirow{2}{*}{0.013} \\
\hline Weekends & $75(38.1)$ & $122(61.9)$ & \\
\hline \multicolumn{4}{|c|}{ Type of arrival } \\
\hline Ambulance & $11^{a}(7.5)$ & $135(92.5)$ & \multirow{3}{*}{$p=0.000$} \\
\hline Car & $206^{\mathrm{b}}(55.1)$ & $168(44.9)$ & \\
\hline On foot & $39^{c}(83.0)$ & $8(17.0)$ & \\
\hline \multicolumn{4}{|l|}{ Color triage } \\
\hline Green & $249(90.9)$ & $25(9.1)$ & \multirow{2}{*}{$p=0.000$} \\
\hline Yellow/red & $7(2.4)$ & $286(97.6)$ & \\
\hline \multicolumn{4}{|l|}{ ESI } \\
\hline ESI 1 & - & $22(100.0)$ & \multirow{5}{*}{ - } \\
\hline ESI 2 & - & $54(100.0)$ & \\
\hline ESI 3 & - & $232(100.0)$ & \\
\hline ESI 4 & $174(98.9)$ & $2(1.1)$ & \\
\hline ESI 5 & $82(98.8)$ & $1(1.2)$ & \\
\hline \multicolumn{4}{|c|}{$\begin{array}{l}\text { *There was no statistically significant difference between the variables marked } \\
\text { with the same letter (the significance level was set to } p<0.016 \text { according to } \\
\text { the Bonferroni correction) ED: Emergency department, ESI: Emergency Severity } \\
\text { Index }\end{array}$} \\
\hline
\end{tabular}

those who made more than one attendance within the last 6 months (OR: $0.62 ; 95 \% \mathrm{Cl}: 0.41-0.94)$ were less likely to make IAs (Table 4).

\section{Discussion}

The results showed that during the COVID-19 pandemic period, approximately half of the ED attendances were inappropriate. It was also found that IAs increased during the weekdays and at night. The frequency of IA was high in young people and low in illiterate patients. In addition, employed patients and patients without chronic diseases were found to be more likely to make IAs.

In this study conducted during the COVID-19 pandemic period, the frequency of IA was determined to be $45.1 \%$. In the previous study conducted in the same center using the same descriptive criteria in March 2018 , the frequency of IU was found to be $74.1 \%$ (15). The use of different IU criteria and seasonal differences may limit the comparison of IU rates between studies (10). However, on comparing the results of the current study to a study by Gündüz et al. (15), it is observed that the frequency of IAs decreased during the pandemic period. Similarly, according to Brick et al. (6), the "nonurgent" attendance rate, which was 31.9\% in March 2019, dropped to $7.5 \%$ in March 2020 as a result of the COVID-19 pandemic. Moreover, Czeisler et al. (21)

\begin{tabular}{|c|c|c|c|}
\hline \multicolumn{2}{|l|}{ Inappropriate } & \multicolumn{2}{|l|}{ Appropriate } \\
\hline Diagnosis & n (\%) & & n (\%) \\
\hline R51 headache & $38(14.8)$ & R07.4 chest pain & $22(7.1)$ \\
\hline J06.9 URTI & $29(11.3)$ & $\begin{array}{l}\text { R11 nausea and } \\
\text { vomiting }\end{array}$ & $22(7.1)$ \\
\hline M79.18 myalgia & $22(8.6)$ & W19 fall & $22(7.1)$ \\
\hline Z51.9 medical care & $17(6.6)$ & $\begin{array}{l}\text { R10.4 abdominal } \\
\text { pain }\end{array}$ & $19(6.1)$ \\
\hline R52.9 pain & $15(5.9)$ & $\begin{array}{l}167.8 \text { cerebrovascular } \\
\text { disease }\end{array}$ & $17(5.5)$ \\
\hline \multicolumn{4}{|c|}{ Attendance complaints } \\
\hline Headache & $48(18.8)$ & Abdominal pain & $69(22.2)$ \\
\hline Nausea vomiting & $35(13.7)$ & Nausea vomiting & $53(17.0)$ \\
\hline Joint limb pain & $25(9.8)$ & Joint limb pain & $47(15.1)$ \\
\hline Backache & $23(9.0)$ & Weakness & $34(10.9)$ \\
\hline Throat ache & $22(8.6)$ & Chest pain & $33(10.6)$ \\
\hline \multicolumn{4}{|c|}{ Complaint starting time before attending the hospital } \\
\hline$\leq 3$ hours & $55(21.5)$ & $\leq 3$ hours & $133(42.8)$ \\
\hline$>3$ hours, $<24$ hours & $34(13.3)$ & $>3$ hours, $<24$ hours & $59(19.0)$ \\
\hline 24 hours & $53(20.7)$ & 24 hours & $50(16.1)$ \\
\hline 48 hours & $51(19.9)$ & 48 hours & $40(12.9)$ \\
\hline$>48$ hours & $63(24.6)$ & $>48$ hours & $29(9.3)$ \\
\hline
\end{tabular}


found that, during the pandemic, there was a decrease in the number of ED attendances for health problems such as otitis media, superficial injuries, and sprains and strains for which treatment and care could be provided in primary care. Czeisler et al. (21) also reported that pandemic-related concerns caused potential ED attendees to avoid presenting to the ED. In the current study, the decrease in IAs was presumed closely related

\begin{tabular}{|c|c|c|c|c|c|}
\hline & OR $^{*}$ & $95 \% \mathrm{Cl}$ & B & Wald & Sig. \\
\hline Age & 0.98 & 0.96-0.99 & -0.02 & 7.41 & 0.006 \\
\hline \multicolumn{6}{|l|}{ Marital status } \\
\hline Single & Reference & & & & \\
\hline Married & 1.20 & $0.66-2.15$ & 0.18 & 0.35 & 0.553 \\
\hline \multicolumn{6}{|c|}{ Attendance time } \\
\hline 08:00-15:59 & Reference & & & & \\
\hline 16:00-23:59 & 1.01 & $0.66-1.55$ & 0.01 & 0.00 & 0.948 \\
\hline 24:00-07:59 & 1.97 & $1.14-3.43$ & 0.68 & 5.82 & 0.016 \\
\hline \multicolumn{6}{|l|}{ Attendance day } \\
\hline Weekend & Reference & & & & \\
\hline Weekdays & 2.00 & 1.33-3.02 & 0.69 & 10.91 & 0.001 \\
\hline \multicolumn{6}{|l|}{ Education } \\
\hline Illiterate & Reference & & & & \\
\hline $\begin{array}{l}\text { Primary } \\
\text { education }\end{array}$ & 1.10 & $0.51-2.35$ & 0.09 & 0.06 & 0.808 \\
\hline High school & 1.08 & $0.44-2.66$ & 0.07 & 0.03 & 0.872 \\
\hline $\begin{array}{l}\text { Graduate and } \\
\text { higher }\end{array}$ & 1.33 & $0.48-3.65$ & 0.28 & 0.30 & 0.583 \\
\hline \multicolumn{6}{|l|}{ Chronic disease } \\
\hline Yes & Reference & & & & \\
\hline No & 2.22 & $1.41-3.50$ & 0.80 & 11.82 & 0.001 \\
\hline \multicolumn{6}{|c|}{ Number of attendances in the last 6 months } \\
\hline First & Reference & & & & \\
\hline$>1$ & 0.62 & $0.41-0.94$ & -0.48 & 5.08 & 0.024 \\
\hline \multicolumn{6}{|c|}{ Onset of symptoms } \\
\hline$\leq 12$ hours & Reference & & & & \\
\hline$>12$ hours & 3.36 & $2.27-4.98$ & 1.21 & 36.62 & 0.000 \\
\hline \multicolumn{6}{|l|}{ Profession } \\
\hline Unemployed & Reference & & & & \\
\hline Employed & 1.75 & $1.12-2.73$ & 0.56 & 6.00 & 0.014 \\
\hline \multicolumn{6}{|l|}{ Alcohol use } \\
\hline No & Reference & & & & \\
\hline Yes & 0.36 & $0.15-0.88$ & -1.01 & 5.04 & 0.025 \\
\hline \multicolumn{6}{|l|}{ Smoking status } \\
\hline No & Reference & & & & \\
\hline Yes & 1.46 & $0.90-2.36$ & 0.38 & 2.31 & 0.128 \\
\hline Constant & 1.62 & & 0.48 & 1.21 & 0.272 \\
\hline \multicolumn{6}{|c|}{ *Odds ratio, Cl: Confidence interval } \\
\hline
\end{tabular}

to concern about the pandemic. Furthermore, during the pandemic period, social restrictions and curfews can be considered among other main factors that may reduce the IA rate.

The attendances in the ESI 1 category constituted 3.9\% of all attendances and code-red attendances were $25.2 \%$ of all attendances. Gündüz et al. (15) reported that the proportion of ESI 1 category attendances was $1.8 \%$ and the proportion of red-coded attendances was $8.8 \%$. The results obtained from the studies conducted at the same center before and during the COVID-19 pandemic period showed that the attendances with high-level urgency increased significantly during the COVID-19 pandemic. The clinical picture worsens and the level of urgency increases as a result of delaying attendance because of concern about getting infected during the pandemic period.

During the COVID-19 pandemic, there were more IAs at night than in the daytime. Conversely, it was reported by Gündüz et al. (15) and for other studies conducted around the world that IAs were concentrated in the daytime (08:00-18: 00), while attendances made at night were more urgent $(22,23)$. However, other studies have reported that IAs increase after working hours owing to difficulties accessing primary healthcare services $(24,25)$. During the COVID-19 pandemic period, patients may prefer to attend ED at night for non-urgent health problems because there are likely to be fewer people so the contact risk is lower.

The rate of IAs was higher on weekdays than on weekends. This finding is consistent with the study by Gündüz et al. (15). On the contrary, in Eroğlu et al. (25) study in Turkey and McHale et al. (23) study in the UK, it was reported that the highest numbers of IAs were on Saturday. The current study center is located within the university campus so the high IA rate during the week before the pandemic is thought to be related to university students preferring the center for non-urgent health problems. In addition, the curfew applied on weekends may have caused higher rates of weekday IAs.

The IA rate was higher in the young. Similarly, in the majority of studies worldwide $(9,10,26)$ the frequency of IA was found to be higher in the young. However, there are also studies showing that the frequency of IA is not affected by age $(27,28)$. The presence of chronic diseases in the elderly and their care needs being more complicated than those of young people are among the reasons why attendances are more urgent in this age group (29). Furthermore, during the COVID-19 pandemic in Turkey, the strict curfew for those over 65 years old may have a protective effect against some health problems because they are staying home and not falling, having accidents etc. 
The frequency of IA was lower in illiterate individuals compared to others. This result is thought to be related to the fact that the majority of illiterate individuals are over 65 years old. It was also determined that employed people made more IAs. This difference may have arisen from unemployed people avoiding going outside unless it is essential during the pandemic.

The majority of IAs were made due to headaches and the second most common reason for IAs was upper respiratory tract infection (URTI). Gündüz et al. (15) reported that URTI was the most frequent reason for IAs. Comparing two studies, the decrease in URTI-related IAs during the pandemic period may be associated with the social distancing rules and the use of masks to control the spread of respiratory-borne diseases. Examing the prepandemic literature, the most common causes of IAs are URTI and pain $(26,27,30,31)$.

\section{Study Limitations}

Our work clearly has some limitations. Conducting the research in a single-center is the main limitation of the study. Furthermore, the study period was limited to one week and it was conducted only during the post-peak period of the pandemic, and other periods of the pandemic (the initial and peak periods, and when restrictions were lifted) were not compared with the non-pandemic periods. In addition, the fact that the study was conducted in Ramadan month creates an important limitation for the study because fasting can have a confounding effect on ED attendance.

\section{Conclusion}

This study showed that the rate of IU decreased and the urgency level of the attendances increased during the COVID-19 pandemic period. There were more IAs at night than during the daytime. There was an inverse relationship between the frequency of IA and age. The results of this study are important for planning ED resources and increasing service capacity during pandemics. In this regard, multi-center studies on a large sample are needed.

\section{Author Contributions}

Concept: P.S., A.G., E.I., O.B., E.U., M.T., Design: P.S., A.G., M.T., Data Collection or Processing: E.I., O.B., E.U., Analysis or Interpretation: P.S., M.T., A.G., Literature Search: P.S., E.I., A.G., M.T., O.B., E.U., Writing: P.S., M.T., A.G., E.I.,

Conflict of Interest: No conflict of interest was declared by the authors.

Financial Disclosure: The authors declared that this study received no financial support.

\section{References}

1. World Health Organization. Emergency WHO DirectorGeneral's opening remarks at the media briefing on COVID-19-11 March 2020. Available from: https://www.who. int/director-general/speeches/detail/who-director-generals-opening-remarks-at-the-media-briefing-on-covid-19---11march-2020

2. Perlini S, Canevari F, Cortesi S, et al. Emergency Department and Out-of-Hospital Emergency System (112-AREU 118) integrated response to Coronavirus Disease 2019 in a Northern Italy centre. Intern Emerg Med 2020;15:825-33.

3. Cao Y, Li Q, Chen J, et al. Hospital Emergency Management Plan During the COVID-19 Epidemic. Acad Emerg Med 2020;27:309-11.

4. Hartnett KP, Kite-Powell A, DeVies J, et al. Impact of the COVID-19 Pandemic on Emergency Department Visits-United States, January 1, 2019-May 30, 2020. MMWR Morb Mortal Wkly Rep 2020;69:699-704.

5. Wong LE, Hawkins JE, Langness $S$, et al. Where are all the patients? Addressing COVID-19 fear to encourage sick patients to seek emergency care. NEJM Catalyst 2020.

6. Brick A, Walsh B, Keegan C, Lyons S. COVID-19 and emergency department attendances in Irish public hospitals. ESRI Series QEC Special Article Dublin. Accessed 2020;1-18.

7. Chen TA, Lai KH, Chang HT. Impact of a severe acute respiratory syndrome outbreak in the emergency department: an experience in Taiwan. Emerg Med J 2004;21:660-2.

8. NHS Hull University Teaching Hospital. Help keep Hull's A\&E for medical emergencies during COVID-19. Available from: https://www.hey.nhs.uk/news/2020/05/05/help-keep-hullsae-for-medical-emergencies-during-covid-19/. Accessed June 25, 2020.

9. Carret ML, Fassa AC, Domingues MR. Inappropriate use of emergency services: a systematic review of prevalence and associated factors. Cad Saude Publica 2009;25:7-28.

10. Uscher-Pines L, Pines J, Kellermann A, Gillen E, Mehrotra A. Emergency department visits for nonurgent conditions: systematic literature review. Am J Manag Care 2013;19:4759.

11. Weinick RM, Burns RM, Mehrotra A. Many emergency department visits could be managed at urgent care centers and retail clinics. Health Aff (Millwood) 2010;29:1630-6.

12. Morley C, Unwin M, Peterson GM, Stankovich J, Kinsman L. Emergency department crowding: A systematic review of causes, consequences and solutions. PLoS One 2018;13:203316.

13. Moskop JC. Nonurgent care in the emergency departmentbane or boon? Virtual Mentor 2010;12:476-82.

14. Uppal A, Silvestri DM, Siegler M, et al. Critical Care And Emergency Department Response At The Epicenter Of The COVID-19 Pandemic. Health Aff (Millwood) 2020;39:1443-9. 
15. Gunduz A, Topbaş M, Gursoy A, et al. Evaluation of frequency, causes of inappropriate attendance to the emergency departments and relationship to overcrowding in Trabzon Province. TUBITAK 3001-Starting R\&D Projects Support Program, No: 216S973;2018.

16. Pala K. COVID-19 pandemic in Turkey. Turkish Physicians Association Sixth Month Evaluation Report for COVID-19 Pandemic. Available from: https://www.ttb.org.tr/ kutuphane/covid19-rapor_6/covid19-rapor_6_Part15.pdf. Accessed February 2, 2021.

17. Keskinkilic B, Shaikh I, Tekin A, Ursu P, Mese EA. World Health Organization. Turkey's response to COVID-19: first impressions 2020;1-23.

18. T.C. Official newspaper. Communique on the Application Procedures and Principles of Emergency Services in Inpatient Health Institution. 16.10.2009. Sayı: 27378, Prime Ministry Printing House, Ankara.

19. Fernandes CM, Tanabe P, Gilboy N, et al. Five-level triage: a report from the ACEP/ENA Five-level Triage Task Force. J Emerg Nurs 2005;31:39-50.

20. Çınar O, Çevik E, Salman N, Cömert B. Emergency Severity Index triage system and implementation experience in a university hospital. Turk J Emerg Med 2010;10:126-31.

21. Czeisler MÉ, Marynak K, Clarke KEN, et al. Delay or Avoidance of Medical Care Because of COVID-19-Related Concerns United States, June 2020. MMWR Morb Mortal Wkly Rep 2020;69:1250-7.

22. Tsai JC, Liang YW, Pearson WS. Utilization of emergency department in patients with non-urgent medical problems: patient preference and emergency department convenience. J Formos Med Assoc 2010;109:533-42.

23. McHale P, Wood S, Hughes K, Bellis MA, Demnitz U, Wyke S. Who uses emergency departments inappropriately and when - a national cross-sectional study using a monitoring data system. BMC Med 2013;11:258.

24. O'Keeffe C, Mason S, Jacques R, Nicholl J. Characterising non-urgent users of the emergency department (ED): A retrospective analysis of routine ED data. PLoS One 2018;13:192855.

25. Eroglu SE, Toprak SN, Urgan O, et al. Evaluation of non-urgent visits to a busy urban emergency department. Saudi Med J 2012;33:967-72.

26. Hakkoymaz H, Okyay RA. How appropriate are the emergency department admissions? A study from a tertiary hospital emergency department. EJMI 2020;4:353-9.

27. Miyazawa A, Maeno T, Shaku F, et al. Inappropriate use of the emergency department for nonurgent conditions: patient characteristics and associated factors at a Japanese hospital. J Gen Fam Med 2019;20:146-53.

28. Jalili $M$, Shirani $F$, Hosseininejad $M$, Asl-e-Soleimani $H$. Emergency department nonurgent visits in Iran: prevalence and associated factors. Am J Manag Care 2013;19:1-8.

29. Lennox A, Braaf S, Smit DV, Cameron P, Lowthian JA. Caring for older patients in the emergency department: Health professionals' perspectives from Australia-The Safe Elderly Emergency Discharge project. Emergency Medicine Australasia 2019;31:83-9.

30. Idil H, Kilic TY, Toker I, Dura Turan K, Yesilaras M. Non-urgent adult patients in the emergency department: Causes and patient characteristics. Turk J Emerg Med.2018;18:71-4.

31. Raven MC, Lowe RA, Maselli J, Hsia RY. Comparison of presenting complaint vs discharge diagnosis for identifying "nonemergency" emergency department visits. JAMA 2013;309:1145-53. 